\title{
Poesía española de la postmodernidad
}

\author{
ANDREW P. DEBICKI \\ Universidad de Kansas
}

Críticos e historiadores literarios de la poesía española destacan una nueva orientación a mediados y fines de los 1940: mencionan la aparición de poemas escritos en un lenguaje directo, la tendencia al "realismo" en la presentación de las cosas, y el surgimiento del tema social'. También notan la presencia de una veta existencialista, aparente en los hablantes angustiado por el mundo que les rodea en poemas de Dámaso Alonso y Blas de Otero. No cabe duda de que la poesía de esta época difiere de la tradición más estetizante de los años 20 .

Me parece algo superficial y peligroso, sin embargo, basarse en estas diferencias para caracterizar los 1940 y 50 como los de cambio más significativo en la poesía española del siglo, y aseverar que marcan el advenimiento de una lírica realista que pone fin a la época anterior de un arte estético (y "deshumanizado»). Tal caracterización tiende a agrupar toda la poesía publicada a partir de la postguerra hasta los 1970 bajo el rótulo de "realista", juntando autores tan dispares entre sí como Gabriel Celaya, Blas de Otero, Angel González y Claudio Rodríguez. Su mayor peligro, tal vez, es el de emplear un fe-

1. Ver Víctor García de la Concha, La poesía española de posguerra (Madrid, Ed. Prensa Española, 1973), pp. 293-420; Santos Sanz Villanueva, Historia de la literatura española 6/2: literatura actual (Barcelona, Ed. Ariel, 1984), pp. 341-70; y especialmente el extenso ensayo introductorio de José María Castellet a Veinte años de poesía española, 1939-1959 (Barcelona, Seix Barral, 1960). 
nómeno histórico puramente español -la guerra civil-y aspectos puramente temáticos -lo social, por ejemplo- como determinantes de tendencias y períodos literarios. Esto, a mi modo de ver, produce por lo menos dos efectos bien indeseables. Primero, tiende a ignorar ciertos cambios de estilo, enfoque y perspectiva que ocurren en la poesía española de postguerra, principalmente a partir de 1960, y que tal vez sean mucho más importantes que la entrada del tema social en los 1940. Segundo, y relacionado con lo anterior, nos obliga a ver la poesía española aparte del contexto artístico y cultural del mundo occidental. Específicamente, ignora posibles relaciones entre los cambios que ocurren en la poesía española de las dos últimas décadas y el paso desde la «modernidad» a la "postmodernidad» en las artes occidentales- paso que ha sido ampliamente discutido en otros países (pero, hasta hace poco, no en España), y que se relaciona con cambios fundamentales en las estéticas dominantes y en las actitudes tomadas ante una obra de arte.

Por eso quisiera hacer destacar en este trabajo otros cambios que ocurren en la poesía española de las últimas décadas, y que tienen más que ver con el enfoque de! poema, el juego de perspectivas y ciertos rasgos metapoéticos que con su temática. Los poemas que voy a comentar se distinguen por su empleo simultáneo de diversos niveles de lenguaje y de diversas perspectivas, que nunca se resuelven en un significado unitario, dejando al lector la tarea de barajarlos y llegar a alguna conclusión. En muchos casos, esto se combina con alusiones al poema mismo y a sus procedimientos dentro del texto, motivando un rompimiento de la convención de que la realidad descrita en la obra es una ficción separada de la realidad del autor (y del lector). Todas estas tensiones, irresoluciones y aspectos metapoéticos podrán relacionarse, en mi opinión, con la pérdida de confianza en la unicidad e inmutabilidad de la obra que se ha visto como el paso desde la modernidad a la postmodernidad.

Las características a las que apunto no aparecen súbitamente en los 1960. Podemos hallarlas en algunas obras de la primera mitad del siglo veinte: en otro sitio, he sugerido que en las tensiones y ambigüedades de Seguro azar de Pedro Salinas podemos ver un anticipo de la postmodernidad ${ }^{2}$. Pero la nota dominante de la Generación de 1927

2. Ver mi «Pedro Salinas, precursor de la postmodernidad», en prensa en Puertaoscura; revista de ultramarinos. 
es, evidentemente, la creencia en, y la creación de obras de gran coherencia y estabilidad. Tal confianza empieza a derrumbarse en la época de la postguerra. Ya podemos ver indicios de las características "postmodernas" a las que he aludido en Hijos de la ira de Dámaso Alonso, publicado en 1945. En su poema inicial, titulado «Insomnio», se baraja un tono desesperadamente romántico con expresiones cotidianas, creando una mezcla heterogénea de diversos niveles de lenguaje. Aunque el hablante del poema hasta cierto punto integra estos niveles en su actitud, no los resuelve completamente. El poema, en este sentido, se aparta de una premisa fundamental de la poesía moderna a partir del simbolismo (y que subyace también en la crítica analítica tradicional): que la obra literaria es una estructura estática y coherente, que contiene en si un significado definible. En contraste, por ejemplo, con el poema "Perfección» de Jorge Guillén, "Insomnio» no encarna en su lenguaje una sola experiencia definible. Más bien se vale de varios niveles de lenguaje para suscitar en el lector varias visiones de un ser humano y de una sociedad en crisis.

Esta manera de poetizar, sin embargo, aunque ya discernible, no domina la primera época de la postguerra en España. Los poemas más influyentes y conocidos de Blas de Otero, de Gabriel Celaya, y de otros autores de la Antología consultada tienden, al contrario, a encarnar claramente visiones bien coherentes de los problemas sociales y existenciales. Si bien resultan innovadores en su temática y en su empleo de un lenguaje cotidiano, caben dentro de la tradición moderna, de acuerdo con la cual el poema es depositario de un significado estable y determinable. Ciertos rasgos de esta poesía, como el empleo de recursos formales tradicionales, de la metáfora, y de la forma del soneto por parte de Blas de Otero y Gabriel Celaya, confirman la impresión de que en muchos sentidos su obra no ha dejado atrás la poesía de la modernidad. Sólo en su poesía más tardía Otero creará, por medio de collages e intertextualidades, obras más abiertas, como lo harán, con procedimientos diferentes, Celaya y José Hierro. Más indicios de las mezclas de niveles y perspectivas a las que estoy aludiendo se encontrarán en la poesía de Carlos Edmundo de Ory, cuya importante obra pasaba desapercibida en los años 1950 y 1960.

Donde sí aparecen más a menudo poemas de índole abierta es en la segunda época de la poesía de postguerra, época que yo vería abarcando desde fines de los 1950 a principios de los 1970. Los nuevos poetas que se destacan en este tiempo habían nacido entre 1925 y 1938, y se formaron cuando el asunto social y el lenguaje cotidiano 
predominaban. Como ya se ha notado, era su tarea profundizar las posibilidades artísticas de este lenguaje, lo que ha llevado a varios críticos a considerar su obra como más derivativa que revolucionaria $^{3}$. A mi modo de ver, sin embargo, su manera de poetizar confirma y subraya ( $s i$ no introduce) cambios de perspectiva y de efecto que resultan más importante que la aparición del tema social en los 1940.

Para entender la aportación de estos poetas, vale recordar sus ideas acerca de la función de la poesía. Casi todos destacan el valor del poema como acto de conocimiento, de descubrimiento. Subrayan que el significado del poema no recoge significados previamente existentes, sino que surge en el proceso de su composición. En palabras de José Angel Valente, "Todo poema es, pues, una exploración de materia de experiencia no previamente conocida [...] porque todo poema es un conocimiento haciéndose ${ }^{4}$. También atribuyen un papel más importante al lector, que viene a ser co-partícipe en el descubrimiento de nuevos significados. Como ha notado Enrique Badosa "En la poesía el poeta se conoce más a sí mismo y a las cosas, gracias al poema, e -igual que el lector-tiene ocasión de hallarse en una nueva experiencia...." ${ }^{5}$. Y Angel Gozález, en un discurso reciente, habla de la manera en que las palabras del poema pueden "manifestarse en libertad con independencia de los designios de quien las escribe" para, a fin de cuentas, actualizar "posibilidades expresivas que subyacen, olvidadas o inéditas, en el idioma " ${ }^{6}$. Tales actitudes modifican, desde luego, la postura utilitaria de los poetas sociales de la primera postguerra. Pero tienen una importancia mucho más fundamental: sobre. ponen a la visión tradicional y "moderna" de una obra permanente e inmutable, el concepto de un texto abierto, importante no como depósito de significados sino más bien como estímulo a continuos descubrimientos, lecturas y relecturas. En este sentido, se relacionan con actitudes en la literatura, en el arte, y en la arquitectura que críticos e historiadores occidentales han ligado con la época de la "postmo-

3. Ver José Olivio Jiménez, "Medio siglo de poesía española (1917-1967)». Hispania (U.S.A.), 50, núm. 4 (1967), p. 943; y Sanz Villanueva, op. cit., pp. 400-17.

4. J.A. Valente, Las palabras de la tribu (Madrid, Siglo XXI de España, 1971), p. 7.

5. E. Badosa, «Primero hablemos de Júpiter (la poesía como conocimiento)», Papeles de Son Armadans, 10, núm. 29 (1958), pp. 149-50.

6. A. González, Palabras pronunciadas por A.G. en el acto de entrega de los Premios Principe de Asturias (4 de Octubre de 1985), edición no venal dẹ Manuel Lombardero, Gijón, 1985. 
dernidad" (pensemos, sólo como ejemplo, en los edificios del grupo "Site», deliberadamente construidos para que parezcan estarse derrumbando, o en pintores "conceptuales" que toman fotografías del público contemplando sus cuadros, y luego exhiben estas fotografías como nuevas obras de arte $)^{7}$.

Podremos ver las características y los efectos de una poesía abierta en muchas obras de Angel González. Vale recordar que su poesía trata una gran variedad de temas: tiene por una parte una importante dimensión social, con muchos poemas que satirizan el mundo español de su época. Por otra, revela una veta elegíaca, con obras centradas en los estragos causados por el tiempo. También abundan asuntos amorosos y eróticos, y el tema mismo de la creación poética. Las características más originales de esta poesía residen no tanto en sus temas, ni siquiera en sus rasgos estilísticos, como en su tono, su perspectiva, y su efecto. Como he indicado en otra parte, son muy importantes las maneras en que González transforma realidades conocidas, invierte las perspectivas, comenta irónicamente los asuntos tratados, o crea juegos intertextuales ${ }^{8}$. Todo esto sirve a menudo para involucrar al lector en el texto e invitarlo a participar en su proceso de creación y recreación.

Podremos verlo en "Empleo de la nostalgia», de Procedimientos narrativos, que comienza así:

7. Acerca de la postmodernidad, son fundamentales el libro de Jean-François Lyotard, The Postmodern Condition (1979) (Minneapolis, Univ. of Minnesota, 1984; la versión en español La condición postmoderna, se publicó por Ed. Cátedra en 1984); Ihab Hassan, Paracriticisms (Urbana, Univ. of Illinois, 1984), cap. 2; y Matei Calinescu, Five Faces of Modernity (Durham, Duke Univ. Press, 1987), pp. 263-312. El término "post-modern" se ha aplicado con cierto rigor a la poesía inglesa y norteamericana por Jerome Mazzaro en Postmodern American Poetry (Urbana, Univ. of Illinois Press, 1980). En arquitectura, como nota Calinescu (pp. 281-284), se relaciona con la vuelta a formas complejas y contradictorias. En España "postmoderno» parece emplearse más en la expresión popular y relacionarse con fenómenos culturales más bien superficiales.

Importa aquí destacar el hecho de que hace ya muchos años Carlos Bousoño desarrolló el concepto de poesía "postcontemporánea", atribuyéndole algunas características que ahora se relacionan con la postmodernidad; en este sentido debe reconocerse su aportación innovadora e importante. Ver Bousoño, "Poesía contemporánea y poesía postcontemporánea», incluído como apéndice a Teoría de la expresión poética. 5. ed., tomo 2 (Madrid, Ed. Gredos, 1970), pp. 277-319. Bousoño, sin embargo, pone énfasis en ciertas características como el empleo del lenguaje vulgar y familiar, el realismo, y el enmascaramiento del individuo que, aunque importantes en la poesía española de postguerra, no se relacionan con el fenómeno del texto multivalente que para mí constituye un aspecto esencial de la postmodernidad.

8. Ver Debicki, Poesía del conocimiento (Gijón, Júcar, 1987), pp. 109-38. 


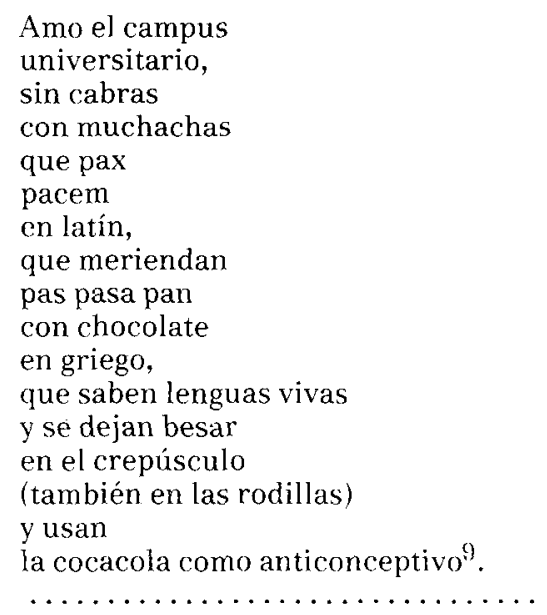

Se destaca, desde luego, una visión jocosa e irreverente de estudiantes modernas en un "campus" universitario norteamericano. Juegos de palabras («lenguas») contraponen irónicamente estudio y actividad sexual; vocablos que aluden a los casos del latín se mezclan con alusiones a la merienda; un lugar común romántico (besos en el crepúsculo) da paso a un detalle sexual concreto. Por detrás de la escena cómica, se nos ofrece una contraposición de diversas realidades y diversos niveles de expresión.

Surgen aquí evidentes correspondencias intertextuales: las alusiones al placer y la actitud del hablante hacen de este trozo una elaboración y una parodia del tópico pastoril y del «beatus ille», mientras que el beso en el crespúsculo evoca la poesía romántica. El poema parece una versión venida a menos de tradiciones líricas amorosas. Lleva al lector a reirse del mundo moderno por una parte, pero también a modificar su actitud ante las tradiciones, por otra. Después de leer este texto, ¿podríamos mirar seriamente un poema pastoril o una obra amorosa del siglo diecinueve? Un efecto central de estas contraposiciones e intertextualidades es el de hacernos modificar nuestras actitudes habituales ante toda una serie de realidades, sin integrarlas o resolverlas en una visión total.

El resto del poema consta de varias secciones que se mezclan y

9. Cito de A. González, Palabra sobre palabra (sus poesias completas, publicadas por la ed. Seix Barral en Barcelona en 1986), p. 247. Procedimientos narrativos se publicó por primera vez en 1972. 
se alternan, mezclando visiones serias y cómicas. Una consta de versos en letra redonda, a la izquierda de la página. Leída aparte, ofrece una visión bella de recuerdos académicos. Se intercalan con ella, sin embargo, versos en bastardilla a la derecha de la página, con alusiones explícitas a un acto sexual. Ambas secciones pueden leerse aparte, o juntas; contraponen perspectivas opuestas que el hablante parece estar barajando, y que el lector puede escoger o combinar de varias maneras. Luego, el poema termina con un comentario aparentemente serio del hablante, que se da cuenta de las pérdidas causadas por el tiempo y del valor limitado de los recuerdos. En vista de las secciones anteriores, pudiéramos ver este final como una recapitulación de lo que ya habíamos experimentado al leer el poema: las intertextualidades, las mezclas de niveles y los cambios de perspectiva ya nos habían hecho sentir lo relativo, impreciso e inestable de una realidad recordada.

La diferencia de tono entre este final y el principio jocoso pudiera dejarnos algo desorientados; en vista del tono chistoso inicial, ¿hasta qué punto hemos de tomar en serio el tema de las pérdidas motivadas por el tiempo? En nuestra desorientación, sin embargo; late gran parte del efecto de este texto. Aunque trata un tema evidente, lo hace desde perspectivas y con tonos contradictorios. Así niega la unidad, la permanencia, y la resolución orgánica que esperábamos de una obra "moderna». Deja en cambio un enigma, un espacio en blanco: nos obliga a tratar, por nuestra propia cuenta, de reconciliar sus tonos. (Podemos ver el principio más como pretexto para llevarnos al tema central de las pérdidas; o podemos ver el poema como más parodia de esté tema que otra cosa. Las secciones se minan, se subvierten). Se ejemplifica aquí algo de la "discontinuidad juguetona» que Ihab Hassan considera típica de la postmodernidad, y como ejemplo de la reacción postmoderna en contra de los principios de unidad orgánica y de trascendencia que regían la época moderna a partir del simbolismo ${ }^{10}$.

Efectos afines se hacen aún más evidentes en otro libro de González, titulado Muestra, corregida y aumentada, de algunos procedimientos narrativos y de las actitudes sentimentales que habitualmente

10. Ver I. Hassan, op. cit., pp. 24-25 y 56-58. Marjorie Perloff, en The Poetics of Indeterminancy: Rimbaud to Cage (Princeton, Princeton University Press, 1981), indaga las características de una poesía irresuelta, cuyos orígenes encuentra en Rimbaud pero cuyo desarrollo ve especialmente en las últimas décadas. 
comportan. ${ }^{11}$ Como ya ha notado Martha LaFollette Miller, este título contradice una de las convenciones de la lírica tradicional: llama la atención más hacia el proceso de escribir, hacia la técnica, que hacia las experiencias tratadas por el libro ${ }^{12}$. No podemos tomar esta contradicción completamente al pie de la letra, ya que el libro trata asuntos y temas serios y personales. Pero sirve, sin duda, para orientarnos en nuestra lectura, y desmentir la expectativa de recibir una obra cerrada que siga los principios de coherencia y verosimilitud dominantes en la poesía de la tradición moderna.

Todo esto se ve bien claro en «Calambur»:

La axila vegetal, la piel de leche, espumosa y floral, desnuda y sola, niegas tu cuerpo al mar, ola tras ola, y lo entregas al sol; que le aproveche.

La pupila de Dios, dulce y piadosa, dora esta hora de otoño larga y cálida, y bajo su mirada tu piel pálida pasa de rosa blanca a rosa rosa.

Me siento dios por un instante; os veo a él, a ti, al mar, la luz, la tarde.

Todo lo que contemplo vibra y arde, y mi deseo se cumple en mi deseo:

dore mi sol así las olas y la espuma que en tu cuerpo canta, canta -más por tus senos que por tu gargantado re mi sol la si la sol la si la.

La forma del poema -cuartetos endecasilábicos- evoca inmediatamente la poesía renacentista o barroca; igual lo hace el tópico de la bella mujer a la que alaba el hablante, la imagen de "la piel de leche», y muchos de los vocablos empleados en las dos primeras estrofas. Surge cierta tensión entre estos elementos clásicos y nuestra percepción de que se trata simplemente de una muchacha que prefiere tomar el sol a nadar. Pero esta tensión, aunque revela que estamos ante una adaptación contemporánea de una tradición antigua, cabría muy

11. Muestra se publicó por primera vez en 1976 (la versión corregida y aumentada es de 1977). La cita de "Calambur" procede de Palabra sobre palabra (1986), p. 298.

12. Ver M. Miller, "Literary Tradition Versus Speaker Experience in the Poetry of Angel González», Anales de la Literatura Española Contemporánea, 7 (1982), pp. 79-95; y Douglas Benson, «Angel González y Muestra: las perspectivas múltiples de una sensibilidad irónica", Revista Hispánica Moderna, 40 (1978-1979), p. 44. Acerca de "Calambur», ver N. Mandlove, "Used poetry...", en Rev. Canadiense de Estudios Hispánicos, 7 (1983), pp. 301-306. 
bien en la poesía moderna -piénsese, por ejemplo, en Cal y canto de Rafael Alberti. No destruye la línea demarcatoria tradicional entre el asunto de la obra por una parte, y el proceso de componerla por otra.

Más sorprendente es el conflicto entre la manera en que comienza el poema y su título; mientras que éste llama la atención hacia un procedimiento, aquélla enfoca una escena, un personaje y una tradición de poesía amorosa. Aquí sí se rompe la división entre asunto (el supueso "propósito" de una obra) y procedimiento (un recurso para comunicar el asunto). Se nos anuncia que el poema no será lo que parece, que el supuesto tema de la muchacha tal vez no sea lo central, que habrá una dimensión técnica o metapoética. Nuestra lectura no podrá seguir inocentemente el tópico, sino que aguardará el «calambur" y el juego.

Seguimos aguardando a medida que leemos la segunda estrofa, sin llegar todavía al calambur prometido. Pero nuestra disposición nos hace cuestionar la imagen del «dorar», que alude explícitamente a la mirada de Dios - pero que también es aplicable a los efectos del sol en la piel de la niña. De nuevo se produce una tensión parecida a la de la primera estrofa: la solemnidad de la "pupila de Dios" y el lenguaje de toda la estrofa contrastan con la viñeta de la muchacha tan típica de nuestra propia época, tratando de obtener el color deseado para su piel. Esta tensión tampoco rompe los limites entre asunto y procedimiento, pero subraya la diversidad de perspectivas, nos hace seguir fijándonos en el empleo del lenguaje, y nos mantiene esperando otros cambios.

En la tercera estrofa, el hablante pone énfasis en su propia perspectiva. En un sentido, la mención que hace de su propio deseo cabe dentro de la tradición de la poesía amorosa clásica: la mención del "vibrar y arder" bien pudiera hacernos pensar en el amante de ur poema de Garcilaso. Pero la manera en que este hablante contempla, distanciado, la escena y su asunto es mucho menos tradicional. Otorga al poema una perspectiva más contemporánea (creando un efecto algo parecido al de las tensiones que vimos en estrofas anteriores). Además, al hacernos pensar en el papel de hablante como comentarista y poeta de esta escena, sugiere, por lo menos implícitamente, un borrar de los límites convencionales entre el asunto de la obra y el proceso de narrar este asunto. Esto queda apoyado por el significado algo ambiguo de su "deseo»: éste, que en un poema renacentista aludiría a la muchacha como objeto amoroso, parece referirse, por lo 
menos en parte, a la contemplación de toda la realidad descrita por parte del hablante. Cuando su "deseo" se cumple en "su deseo", ¿no pudiéramos ver una alusión al proceso mismo de poetizar la escena? El tema externo y el proceso de presentarlo poéticamente empiezan a confundirse.

La última estrofa retoma la imagen del dorar, aplicándola a las olas igual que a la muchacha y subrayando el efecto sensual de ésta; entonces, de repente, suelta el calambur prometido en el título, transmutando el dorar del sol en las notas musicales «do re mi sol». La aparición tan abrupta del calambur quita el enfoque del asunto de la muchacha y lo pone en el lenguaje en sí: el poema acaba haciéndonos sentir cómo las mismas letras y los mismos sonidos crean un significado totalmente diferente. Al hacerlo, destruye la división de planos entre temas y procedimiento o técnica, y contradice la premisa, tan común en épocas anteriores, de que el procedimiento no es más que un vehículo para encarnar el tema y el significado.

Al hacer que el procedimiento pase a primer plano, este poema viene a ser un comentario sobre su propio proceso de poetizar, sobre el escribir un calambur basado en el asunto de la muchacha en la playa. Y esta característica metapoética abre sus posibilidades: para un lector, el proceso de poetizar puede resultar más importante, para otros menos. Además, al contraponer varias perspectivas y tradiciones - la de un poema renacentista de alabanza a la dama, la de una modificación moderna de tal poema, la de un comentario del hablante-poeta, la de una obra metapoética fundada en un calambur-el texto nos lleva a contemplarlo desde cierta distancia, y verlo como estímulo y motivo para lecturas y relecturas. (La intertextualidad con la poesía renacentista, en efecto, puede motivar una "relectura» de poemas amorosos de esta época).

El énfasis en el procedimiento y el aspecto metapoético de este poema, y del libro del que procede, es algo que Angel González mismo ha comentado en su obra, relacionándolo con cierta decepción suya con el mundo y el lenguaje y con un deseo de dejar atrás un previo "personaje poético" ${ }^{13}$. Pero corresponde también a características que se han comentado a menudo en la literatura de la postmodernidad. Como ha notado Jean-François Lyotard, surge la tendencia de

13. Ver la "Introducción» de González a sus Poemas (Madrid, Ed. Cátedra, 1982), pp. 21-22. 
hacer del texto un "evento": ante la desconfianza en la posibilidad de crear obras de valor único e incambiable, el escritor enfoca el proceso de escribir y de leer ${ }^{14}$. Y el texto que enfoca sus procedimientos y se comenta a sí mismo apunta, como hemos visto en "Calambur", no sólo a múltiples lecturas sino también a una atención al proceso mismo de su composición y su lectura. Su autorreflexividad también rompe el canon ( $\tan$ central a la época moderna) de la obra como mundo aparte, circunscrito por límites textuales de toda otra realidad (incluso la del autor y la del lector). Este canon, como ha demostrado Gustavo Pérez Firmat, se ha roto en ciertas obras claves antes de nuestra época, pero se desmorona especialmente en la literatura y la crítica de la postmodernidad ${ }^{15}$.

Hallaremos algunos de los mismos rasgos en obras de otros poetas de la segunda época de la postguerra. Muchos poemas de Claudio Rodríguez involucran al lector en un constante juego de perspectivas, en que los mismos elementos adquieren valores opuestos. Y el poema "Hilando", de El vuelo de la celebración, enfoca un personaje de un cuadro de Velázquez, le imparte nuevas características (casi pudiera decirse "vida propia»), y nos deja cuestionando las relaciones entre la realidad del cuadro, la del poema y la de un personaje tal vez existente fuera de ambas ficciones. Francisco Brines, en Insistencias en Luzbel, invierte valores tradicionales relacionado con Dios, con el demonio, con aspectos del amor; José Angel Valente tuerce episodios míticos de la Biblia y de la Odisea para obligarnos a ver la realidad desde múltiples y distintos ángulos. Las mezclas de niveles, los aspectos metapoéticos, y la consecuente abertura del texto que hemos examinado en "Calambur» son características de gran parte de la poesía de esta época. E identifican esta poesía con una corriente mundial estética y literaria de la postmodernidad.

Los rasgos que he notado se acentúan aún más en las obras de poetas posteriores. Tal vez sean más evidentes en la metapoesía de

14. J.F. Loytard, The Postmodern Condition, pp. 81-82.

15. Ver G. Pérez Firmat, Literature and Liminality: Festive Readings in the Hispanic Tradition (Durham, Duke University Press, 1986). Este excelente libro ejemplifica en muchos sentidos una perspectiva de la postmodernidad, al enfocar el traspasar de límites y ciertos efectos desintegradores de obras literarias.

El traspasar de los límites textuales implica privilegiar el acto literario y la realidad artística por encima de la realidad, del "yo" del poeta o del hablante. Esto adquirirá especial importancia en las obras de poetas más jóvenes como Guillermo Carnero y Pere Gimferrer. 
Guillermo Carnero, ya estudiada perspicazmente por Carlos Bouso$\tilde{n} 0^{16}$. La nota esteticista tan central en la obra de Carnero parece ligarla con la poesía de la Generación del 27 (y separarla de la literatura de la primera postguerra). Pero tal ordenación, certera desde el punto de vista de los temas, de la actitud general y de algunos rasgos estilísticos, esconde los caminos por los que Carnero continúa e intensifica la nueva veta del texto abierto o «indeterminado" que he estado comentando.

Una de las tensiones centrales de Dibujo de la muerte, primer libro de Carnero, surge entre una aseveración del perdurar del arte por un lado, y un sentido de desgaste y mortalidad por otro ${ }^{17}$. Pero en vez de resolverse en alguna visión paradójica pero integrada (como esperaríamos en un poema de la modernidad), esta tensión desencadena múltiples conflictos y contradicciones, que nos dejan ante va rias perspectivas diferentes y varios niveles de creación lingüística.

Podemos comprobarlo en "Avila", que empieza su visión de la ciudad enfocando el arte de un monumento funerario. Se destacan al principio imágenes de animıales y de partes de estatuas "corazones de nácar", "pájaros de ojos vacíos», "cuellos tronchados», "delgados cráneos casi transparentes", "ojos yertos", senos de las Parcas. Técnicamente, algunas de éstas parecen imágenes visuales de partes del monumento, y otras metáforas. Lo importante, sin embargo, es que todas juntas crean la impresión del monumento, y por extensión del arte de Avila, como un mundo orgánico más que una agrupación de objetos. Pero esto sólo marca el comienzo de las tensiones y contradicciones. Por una parte el poema destaca el hecho de que estos elementos, aunque orgánicos, no han vivido nunca. Se trata de un monumento funerario artístico y no de una tumba en sí; de los cuellos tronchados no brota sangre, sino "sólo el mismo mármol»; las mejillas de los niños son "nacidas al mármol para la muerte»; junto a un perro hay "un cuerpo demasiado hermoso para haber vivido». La belleza de este monumento, y de Avila, estriba en el hecho de que consta de objetos

16. El ensayo de Bousoño, "La poesía de Guillermo Carnero", aparece primero como introducción a Carnero, Ensayo de una teoría de la visión. Poesía 1966-1977 (Madrid, Hisperión, 1983), pp. 11-68, y st recoge en Poesia postcontemporánea Gijón, Júcar, 1984), pp. 229-301, con adiciones.

17. Dibujo de la muerte aparece en 1967; las citas de "Avila" proceden de Ensayo de una teoría de la visión, pp. 77-79. Véase los excelentes comentarios de Bousoño, pp. 41-50. 
creados que sólo parecen haber vivido. Esto los eleva, pero hasta cierto punto también los aísla del contemplador humano.

Por otra parte, sin embargo, estos elementos nos parecen desarticulados, cadavéricos. Producen un efecto de morbidez que culmina con la imagen de la cabeza de un perro «muerto en la piedra». Estos objetos artísticos, al representar en un monumento funerario a seres que han vivido y han muerto, adquieren sus características de fugacidad y mortalidad. La visión que se nos ha estado ofreciendo, entonces, sugiere por lo menos dos perspectivas, dos posibles temas, con tradictorios entre sí: que el arte, si bien remeda la vida, está aislado y por encima de ella gracias a su perfección y estilización; y que el arte, al representar e imitar la vida, fatalmente se contagiará de la temporalidad y de la mortalidad de ésta.

Ante estos conflictos, el hablante se desanima y ofrece una visión pesimista:

A pesar de la noche, es imposible reconstruir su muerte.

Ir ensamblando antiguos inciensos y sudarios, medallones, y viene hasta mí el golpeteo de un caballo en los lisos espejos de la noche, es imposible, nadie sabrá, ni esas raíces ni esas pequeñas uvas de humedad y salitre ni ese tenue azabache como el salto de un pájaro que al trasluz se desliza en los atardeceres al fondo de la carne de los ángeles muertos en el mármol. Hay algún bar abierto en donde suena un disco.

Es tan vasto tu reino que no puedo llenarte, pero yo sé que nada hay de ti entre tus libros; en tus palabras, nada puede saberse, nada puedes mostrar.

Importa notar que el hablante comenta la reconstrucción no de la vida de la ciudad, sino de su muerte. En un sentido, parece buscar la visión estética de un mundo inanimado y estilizado -sin lograrlo, ya que sólo puede juntar en su mente fragmentos que no explican nada. En otro, indaga la mortalidad (o la falta de vitalidad) de esta ciudad artística que contempla, y que resulta sujeta a la misma temporalidad y mortalidad que la vida humana. De cualquier modo, sólo recibe indicios de una realidad intrascendente (el bar donde suena un disco). La discontinuidad de su experiencia se refleja aún en la sintaxis del texto, con sus frases amontonadas, sus virajes sintácticos, su falta de progresión lógica. 
Siguiendo los pasos del hablante, el lector se ve sumergido en los conflictos que éste forja, sintiendo todas las ambigüedades engendradas: la intensidad y el valor del arte como elemento estético que nunca ha vivido, su incomprensibilidad e inasequibilidad al contemplador humano, su morbidez y su sujeción a la temporalidad. Estas no se resuelven en una sola explicación. Sí confluyen, en mi opinión, en una doble experiencia trágica, en la cual lo que da trascendencia a la ciudad del arte y la salva del tiempo la hace inasequible al contemplador, mientras que lo que la hace más humana la condena a la muerte. Un lector "moderno" se preguntaría, sin duda, cuál de estas experiencias, o de las tensiones que mencioné antes, es el significado fundamental del poema. Creo que la pregunta no admite respuesta: estamos ante un texto postmoderno, que nos ofrece varios niveles, entrelazados pero tensivos y contradictorios, y nos deja seguir varias direcciones.

El poema termina con un enfoque metapoético:

Por eso, entre el inmenso latido de la noche,

elevado entre un rumor de vides húmedas, es triste no tener ni siquiera un puñado de palabras, un débil recuedo tibio, para aquí, en la noche, imaginar que algún día podremos inventarnos, que al fin hemos vivido.

Por una parte, el sentido de insuficiencia del hablante al no poder configurar en palabras su experiencia, paralela a su anterior sentido de la imposibilidad de captar el arte de Avila, subrayando la inasequibilidad del arte al ser humano. Por otra, su percepción de no tener recuerdos en que basarse para crear una realidad artística («inventarnos") paralela, su anterior pesimismo ante la posibilidad de intemporalizar experiencias en el arte. En ambos sentidos, este comentario final acerca del proceso del hablante-poeta repite y lleva el tema a otra dimensión distinta de todo lo precedente en el poema. Añade a la visión compleja y pesimista de las limitaciones del arte de Avila la visión igualmente compleja y pesimista de las limitaciones del arte del hablante. (¿Sugerirá al lector, tal vez, una visión igualmente compleja y pesimista de las limitaciones de su papel de receptor de estas obras artísticas?).

Aunque "Avila» difiere en muchos sentidos de la poesía posterior de Carnero, en la que cobra mayor importancia la dimensión metapoética y la teoría del arte, ejemplifica la multiplicidad de niveles y 
de perspectivas, la apertura del texto, y su manera de apuntar a lo que no puede captarse con exactitud (invitando al lector, tal vez, a continuar la indagación ${ }^{18}$. Igualmente "postmoderna" que esta poesía me parece la de Pere Gimferrer, con su dimensión metapoética y sus maneras de emplear y a la vez cortapisar visiones y elementos tradicionales. Carlos Bousoño ha sugerido que la metapoesía es una característica de los poetas de este momento, y que se relaciona con su marginación del orden que les rodea y, ante todo, del «lenguaje del poder», el tipo de expresión racional que domina el mundo en que vivimos $^{19}$. Esto los ligaría con escritores y artistas postmodernos de otros países, en cuya creación de textos discontinuos, autorreflexivos y abiertos se ha visto una reacción no sólo en contra del arte de la modernidad sino también en contra de los cánones y ritos del lenguaje y los esquemas formales que prevalecen en nuestro mundo ${ }^{20}$.

Este asunto, sin embargo, es demasiado amplio y complejo para tratar aquí, y nos llevaría más allá del propósito de este trabajo. Pero subraya el valor de seguir pensando en la poesía española del siglo veinte en relación a las actitudes y corrientes más importantes de la cultura occidental, y destaca la importancia de los efectos novedosos de enfoque y perspectiva que he estado examinando aquí. Sobreponiéndonos a las categorías limitativas de "Generación del 27" y "poesía social», y a la ordenación histórica de la poesía española que éstas implican, debemos notar la importancia de un cambio fundamental de orientación que empieza a notarse en algunas obras de los 1920 y 1930, se insinúa en Hijos de la ira, y llega a dominar la poesía a partir de la segunda promoción posterior a la guerra civil. Este cambio reemplaza la noción de una obra cerrada que aspira a guardar significados estables para siempre, con el concepto de un texto multidimen-

18. La poesía posterior de Carnero resulta, por lo tanto, aún más característica de la postmodernidad. En Variaciones y figuras sobre un tema de la Bruyere (1974, incluído en Ensayo...) la dimensión metapoética y el borrar los límites entre creación poética, comentario crítico, y teoría literaria demuestran un total apartarse de las premisas de la obra de la modernidad.

19. C. Bousoño, en Carnero, Ensayo..., pp. 23-30.

20. Sobre este asunto ver Frederic Jameson, The Political Unconscious (Ithaca, N.Y., Cornell Univ., 1981), pp. 17-102; el concepto del «lenguaje del poder» se remonta a las ideas de Michel Foucault; ver su "Discourse on Language" incluido en The Archaeology of Knowledge (New York, Random House, 1972). Es significativo que Foucault nota la necesidad de reestablecer el discurso literario como «eventon (p.229). 
sional, que mediante contraposiciones de niveles y perspectivas sumerge al lector en una experiencia que éste tendrá que continuar y motiva, como hemos visto, obras de gran importancia en la poesía española. Tomándolas en cuenta, podremos ver cómo esta poesía participa de modo muy importante en el paso hacia la postmodernidad de la literatura y las artes occidentales. 